\title{
Phenolic profile and biological activity of table grapes (Vitis vinifera L.)
}

\author{
C. Di Lorenzo ${ }^{1}$, F. Colombo ${ }^{1}$, E. Sangiovanni ${ }^{1}$, S. Biella ${ }^{1}$, L. Regazzoni ${ }^{2}$, L. Peres de Sousa ${ }^{3}$, L. Bavaresco ${ }^{4}$, D. Tomasi $^{5}$, \\ A. Bosso ${ }^{6}$, G. Aldini ${ }^{2}$, M. Dell'Agli ${ }^{1}$, and P. Restani ${ }^{1}$ \\ ${ }^{1}$ Dipartimento di Scienze Farmacologiche e Biomolecolari, Università degli Studi di Milano, Milan, Italy \\ ${ }^{2}$ Dipartimento di Scienze Farmaceutiche, Università degli Studi di Milano, Milan, Italy \\ ${ }^{3}$ Instituto Politecnico de Beja, Beja, Portugal \\ ${ }^{4}$ Dipartimento di Scienze delle Produzioni Vegetali Sostenibili, Università Cattolica del Sacro Cuore, Piacenza, Italy \\ ${ }^{5}$ Consiglio per la ricerca in agricoltura e l'analisi dell'economia agraria - Centro di Ricerca per la Viticoltura, Conegliano Veneto, Italy \\ ${ }^{6}$ Consiglio per la ricerca in agricoltura e l'analisi dell'economia agraria - Centro di Ricerca per l'Enologia, Asti, Italy
}

\begin{abstract}
Table grapes are largely produced and consumed in the Mediterranean area. Furthermore, in the last years, the commercial interest in table grapes and other non-alcoholic grape products has notably increased worldwide. In addition to the nutritional aspects, polyphenol compounds in fresh grapes could exert positive effects on human health. The aim of this study was the characterization of the phenolic pattern of sixteen grape varieties and the evaluation of the associated antioxidant capacity and anti-inflammatory activity at gastric level. The methods used were: 1) Folin-Cocalteau's assay for the quantification of total polyphenol content; 2) High-Performance Liquid Chromatography (HPLC) coupled with Diode-Array Detector (DAD) to perform the quantitative analysis of grapes phenolic fraction 3) DPPH (1,1,-diphenil-2-picrylhydrazyl) spectrophotometric assay for the assessment of radical scavenging activity; 4) assessment of IL-8 release from human gastric epithelial cells to evaluate the anti-inflammatory activity of grape extracts. Some grapes, including seedless varieties, showed that the phenolic pattern was highly correlated with the biological activities, and, in particular, with peel and seeds portion. These results suggest that selected grape varieties could represent, also for consumers who do not drink wine, a source of healthy compounds potentially able to counteract oxidative stress and gastric inflammation.
\end{abstract}

\section{Introduction}

Grape (Vitis vinifera L.) is one of the most widely produced crops in the world, with approximately 75 million tons produced every year: of them, $45 \%$ is used for the production of table grapes, fresh derivatives (e.g. juice), or, alternatively, dried grapes [1].

Grapes are part of the common diet worldwide and, in recent years, the commercial interest in grape-derived products has grown, also due to the decreasing trend of the wine market. This phenomenon is partially a consequence of the WHO concerns versus alcoholic beverages, considered responsible for the increasing misuse/abuse in young people [2]. In parallel, this market situation has stimulated a considerable interest in nonfermented products, especially table grapes, for their potential positive effects on human health. The OIV, in the strategic plan 2015-2019, reports the importance of investigating "the health aspects, nutritional potential and socio-behavioural factors of all non-alcoholic vine-derived products" [3].

As for the nutritional aspects, fresh grapes provide minerals (mainly manganese and potassium), vitamins (vitamins B6, B1 and C) and soluble fibers. Despite the relatively high sugar content $(65 \mathrm{~g} / 100 \mathrm{~g}$ dry weight), the glycemic index (GI) has been classified as medium
$(\mathrm{GI}=45)$, similarly to banana and pineapple [1]. In addition, grapes are a good source of polyphenols: the peel and pulp of grapes contain mainly anthocyanins (red varieties) and flavonols, while seeds are rich in procyanidins. Although the health-promoting effects of these compounds have been widely investigated, especially in cardiovascular area, diabetes and neurodegenerative disorders $[4,5]$, few studies have been performed about their effect on gastric inflammation. One of the main causes of gastritis is the Helicobacter pylori (H. pylori) infection; this gram-negative bacterium colonizes at least $50 \%$ of the world human population [6]. H. pylori infection activates the immune system, responsible for inducing the release of inflammatory cytokines from gastric epithelial cells: Tumor Necrosis Factor-alpha (TNF- $\alpha$ ) and Interleukin8 (IL-8). IL-8 release is generally associated with the pathway of NF-kB, a transcription factor modulating inflammation, apoptosis and cell proliferation. Chronic inflammatory conditions can also generate oxidative stress, which increases NF-kB activation, worsening, in a vicious circle, the pathological condition [7].

Some unfermented products from Vitis vinifera L., such as vine leaves (var. teinturiers) and dried grapes, have shown to be effective in reducing gastric inflammation in in vitro models $[8,9]$ but the effect of phenol compounds from fresh grapes has not been investigated so far. 
On this basis, the aim of this study was the characterization of the phenolic pattern of different grape varieties and the in vitro evaluation of the associated antioxidant and anti-inflammatory properties at gastric level. The contribution to the biological activity of each portion of the fruit (peel, pulp and seeds) from the most promising varieties will be also considered and discussed.

\section{Materials and methods}

Characterization of the phenolic fraction. The quantification of the total phenolic content was performed by applying Folin-Ciocalteu's assay; in parallel, a HighPerformance Liquid Chromatography (HPLC) method, coupled with photodiode-array detector (DAD) was developed and validated to quantify each polyphenol class.

Assessment of the biological activity. The measure of the radical scavenging activity was performed by DPPH (1,1-diphenyl-2-picrylhydrazyl) spectrophotometric assay. As for the anti-inflammatory activity, grapes extracts were assayed for their efficacy in inhibiting IL-8 release from human gastric epithelial cells (AGS): after cellular treatment with TNF- $\alpha$, IL-8 levels were measured by Enzyme Linked Immunosorbent Assay (ELISA).

\subsection{Samples}

Thirteen table grapes and three wine varieties were analysed in this study. Table grapes included six red and seven white varieties. Apart from Red Globe, table grapes included only seedless varieties. Grape varieties and their provenience are reported in Table 1.

Approximately, $50 \mathrm{~g}$ of each sample were homogenated and freeze-dried. For the spectrophotometric and chromatographic analysis, $0.4 \mathrm{~g}$ of each sample were extracted twice with methanol: water $(1: 1, \mathrm{v} / \mathrm{v})$ mixture (final volume $5 \mathrm{~mL}$ ); red and white grapes were centrifuged for 15 minutes at 3000 and 8000 r.c.f. (relative centrifugal force), respectively. The supernatants were collected and filtered on a $0.45 \mu \mathrm{m}$ filter [8].

For the anti-inflammatory activity assay, about $2 \mathrm{~g}$ of freeze-dried samples were extracted twice with $20 \mathrm{~mL}$ of water for 4 and 16 hours, respectively. Then the supernatants were combined. For Exalta and Albarossa varieties, peel, pulp and seeds were separated and extracted using the same procedure [8].

\subsection{Characterization of the phenolic fraction}

\subsubsection{Folin-Ciocalteu's assay}

Total polyphenol content (TPC) was determined according to the method developed by Singleton and Rossi [10].

Aliquots of $300 \mu \mathrm{L}$ from different samples prepared as described above, were solubilized in $1 \mathrm{~mL}$ of a $50: 50$ water:methanol solution (v/v), mixed with $1.5 \mathrm{~mL}$ of FolinCiocalteu's reagent diluted 10 times, and $1.2 \mathrm{~mL}$ of $7.5 \%$ (w/v) sodium carbonate. After $30 \mathrm{~min}$, the absorbance was measured at $765 \mathrm{~nm}$ in a UV-visible spectrophotometer (Varian Cary 50 SCAN, Palo Alto, CA, USA). The polyphenol content in samples was calculated using a linear regression based on increasing concentrations of standard (gallic acid). Results were expressed as equivalents of gallic acid in $\mathrm{mg} / \mathrm{g}$ of fresh weight.

\subsubsection{HPLC-DAD analysis}

Quantitative analysis of the main polyphenol classes (anthocyanins, flavonols, flavanols and phenolic acids) was conducted by HPLC-DAD according to the method developed and validated by Sangiovanni and collaborators [8].

Stock standard solutions were prepared in methanol: water $(50: 50, \mathrm{v} / \mathrm{v})$ and diluted with $0.1 \mathrm{~N} \mathrm{HCl}$ in order to obtain working solutions in the range of $0.1-50 \mu \mathrm{g} / \mathrm{mL}$, apart from standard anthocyanins, ranging from 0.1 to $12.5 \mu \mathrm{g} / \mathrm{mL}$. The analysis was performed using a Synergi 4u MAX-RP 80A $(250 \times 4.60 \mathrm{~mm} 4 \mu \mathrm{m})$ and a gradient elution at a flow rate of $0.8 \mathrm{~mL} / \mathrm{min}$, where $\mathrm{A}$ was water: acetonitrile: formic acid $87: 3: 10(\mathrm{v} / \mathrm{v} / \mathrm{v})$; and B acetonitrile: water: formic acid 50:40:10(v/v/v). The gradient was set as follows: 0-15 min: $94-70 \%$, A, 15-30

\subsection{Assessment of the biological activity}

\subsubsection{Free radical scavenging capacity: $D P P H$ assay}

The antioxidant activity (AOA) of grape samples was measured spectrophotometrically according to the method described by Brand-Williams et al. [11,12]. Samples were prepared as described in 2.1. Aliquots of $1 \mathrm{~mL}$ of 1,1-diphenyl-2-picryl-hydrazyl free radical (DPPH) (Sigma Aldrich, Germany) in methanol $(5 \mathrm{mg} / 100 \mathrm{~mL})$ were mixed with $0.5 \mathrm{~mL}$ of each sample suitably diluted. The absorbance was measured after 30 minutes at $517 \mathrm{~nm}$. Each analysis was performed in triplicate. Results were expressed as equivalents of trolox ( $\mathrm{mg} / \mathrm{g}$ fresh weight).

\subsection{Anti-inflammatory activity}

\subsubsection{Assessment of IL-8 release}

Human gastric epithelial (AGS) cells were treated for $6 \mathrm{~h}$ with grape extracts $(5-100 \mu \mathrm{g} / \mathrm{mL})$, prepared as described in paragraph 2.1 , and the pro-inflammatory stimulus (TNF- $\alpha, 10 \mathrm{ng} / \mathrm{mL})$. IL- 8 release was measured in the culture medium by ELISA (Peprotech Inc., London, UK) and quantified spectrophotometrically at $450 \mathrm{~nm}$, using a standard curve $(8.0-1000.0 \mathrm{pg} / \mathrm{mL})$. Epigallocatechingallate (EGCG) was used as a reference compound for the inhibition of IL-8 release. Each analysis was performed in triplicate.

\section{Results}

\subsection{Characterization of the phenolic fraction}

\subsubsection{Folin-Ciocalteu's assay}

In Fig. 1 is reported the total polyphenol content (TPC) of grape samples included in the study.

TPC ranged between $0.44 \pm 0.02$ and $7.94 \pm 0.19 \mathrm{mg}$ gallic acid equivalents/g of fresh weight, according to data from the scientific literature $[13,14]$ TPC of red wine varieties was higher than that of red table grapes: Albarossa showed the highest phenol content $(7.94 \pm 0.19 \mathrm{mg} / \mathrm{g})$ followed by Barbera and Nebbiolo $(4.08 \pm 0.25$ and $3.85 \pm 0.07 \mathrm{mg} / \mathrm{g}$, respectively). Surprisingly Exalta, which is a white variety, showed the highest TPC $(2.86 \pm 0.04 \mathrm{mg} / \mathrm{g})$ among all table grape samples. The lowest contents were found in the red table 
Table 1. Grape varieties included in study, their provenience and codes used.

\begin{tabular}{|c|c|c|c|}
\hline Var. & Cultivar & Origin & Cod \\
\hline \multirow{4}{*}{ Red table grapes } & Pasiga & Conegliano Veneto, Italy & PA \\
\cline { 2 - 4 } & Red Flame & Conegliano Veneto, Italy & RF \\
\cline { 2 - 4 } & Red Globe & Beja, Portugal & RG \\
\cline { 2 - 4 } & Beauty Seedless & Conegliano Veneto, Italy & BEs \\
\cline { 2 - 4 } & King's Ruby Seedless & Conegliano Veneto, Italy & KRs \\
\cline { 2 - 4 } & Nerona & Conegliano Veneto, Italy & NR \\
\hline \multirow{4}{*}{ Red wine grapes } & Nebbiolo & Asti, Italy & NB \\
\cline { 2 - 4 } & Barbera & Asti, Italy & BR \\
\cline { 2 - 4 } & Albarossa & Asti, Italy & AL \\
\hline \multirow{4}{*}{ White table grapes } & King's Husainy & Conegliano Veneto, Italy & KH \\
\cline { 2 - 4 } & Sugraone B. & Conegliano Veneto, Italy & SC \\
\cline { 2 - 4 } & Exalta & Conegliano Veneto, Italy & EX \\
\cline { 2 - 4 } & Sultanina & Conegliano Veneto, Italy & SL \\
\cline { 2 - 4 } & Canner Seedless & Conegliano Veneto, Italy & CAs \\
\cline { 2 - 4 } & Centennial Seedless & Conegliano Veneto, Italy & CEs \\
\cline { 2 - 4 } & Sugraone & Beja, Portugal & SG \\
\hline
\end{tabular}

min: $70-50 \%$ A, 30-35 min: 50-10\% A, 35-38 min: 10\% A isocratic, 38-48 min: 10-94\% A. The same chromatographic conditions were applied to the other class of flavonoids (flavonols, flavanols and phenolic acids), but a different column was used (Synergi 4u MAX-RP 80A, $250 \times 2 \mathrm{~mm} 4 \mu \mathrm{m}$ ). Anthocyanin and the other class of flavonoids were detected at 520 and $360 \mathrm{~nm}$, respectively, apart from epicatechin (EC) and epicatechin-gallate (ECG), detected at $280 \mathrm{~nm}$. Each analysis was performed in triplicate.

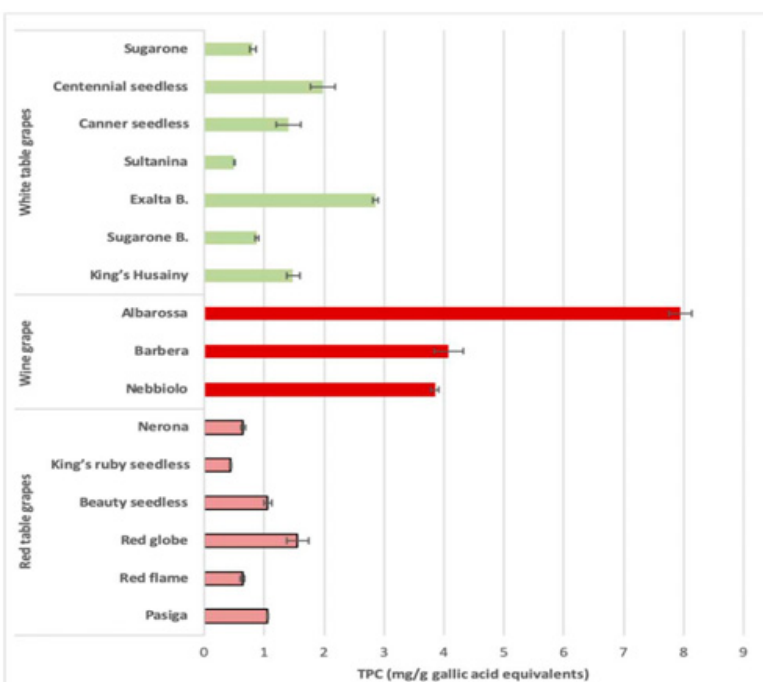

Figure 1. Total polyphenol content (TPC) in grape samples. Data are expressed as $\mathrm{mg} / \mathrm{g}$ of gallic acid equivalents.

grape King's Ruby $(0.44 \pm 0.019 \mathrm{mg} / \mathrm{g})$ and in the white Sultanina $(0.51 \pm 0.003 \mathrm{mg} / \mathrm{g})$.

\subsubsection{HPLC-DAD analysis}

The main classes of polyphenol compounds were quantified by HPLC-DAD, according to the method previously developed and validated [8]. Quantitative analysis of anthocyanins is reported in Fig. 2.

Malvidin-3-O-glucoside was the most representative molecule both in wine and in table grapes: Albarossa and Barbera showed the highest amount $(1067.40 \pm 34.66 \mu \mathrm{g} / \mathrm{g}$ and $653.78 \pm 12.55 \mu \mathrm{g} / \mathrm{g}$, respectively), followed by Beauty seedless $(141.68 \pm 5.63 \mu \mathrm{g} / \mathrm{g})$, Nerona $(71.70 \pm 2.71 \mu \mathrm{g} / \mathrm{g})$, Pasiga $(41.87 \pm 1.25 \mu \mathrm{g} / \mathrm{g})$

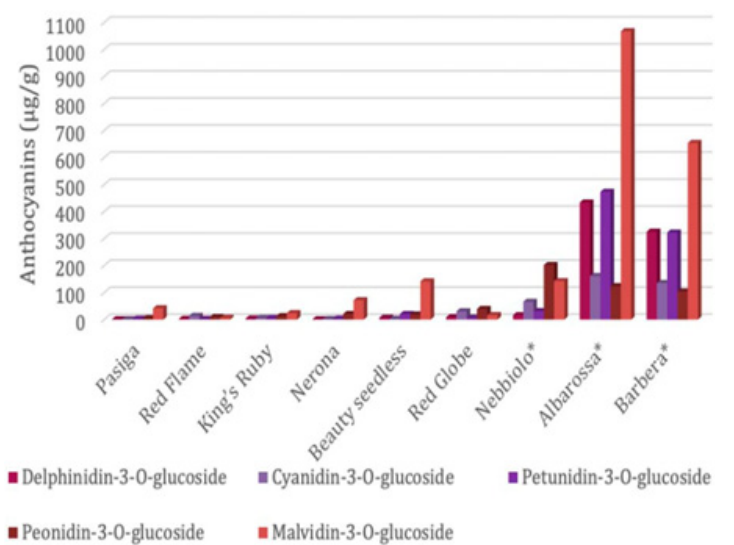

Figure 2. Anthocyanin amounts $(\mu \mathrm{g} / \mathrm{g}$ fresh weight) in red grapes; wine varieties are indicated with $(*)$.

and King's Ruby $(24.00 \pm 0.49 \mu \mathrm{g} / \mathrm{g})$. Interestingly, delphinidin-3- $O$-glucoside was the most abundant compound only in wine varieties, while it was not detected in table grapes. On the other hand, cyanidin-3-O-glucoside and petunidin-3-O-glucoside were the less abundant in all the samples included.

The content of the other classes of flavonoids is reported in Table 2.

Flavonols and flavanols were always the most abundant compounds: among flavonols kaempferol-3$O$-glucoside was detected in all grape varieties, and was particularly abundant in the white Canner seedles $(21.94 \mu \mathrm{g} / \mathrm{g})$. This variety was also rich in quercetin-3$O$-glucoside $(63.80 \pm 1.46 \mu \mathrm{g} / \mathrm{g})$, a flavonol compound, which is abundant in wine and red table grapes, as well. As for flavanols, epicatechin (EC) was present in significant amounts in white varieties, while epicatechigallate (ECG) only in Sultanina and Exalta $(53.87 \mu \mathrm{g} / \mathrm{g}$ and $34.50 \mu \mathrm{g} / \mathrm{g}$, respectively). The total polyphenol content measured by 
Table 2. Amounts of polyphenols in grape samples ( $\mu \mathrm{g} / \mathrm{g}$ fresh weight) expressed as mean \pm standard deviation (SD).

\begin{tabular}{|c|c|c|c|c|c|c|c|c|c|c|c|c|c|c|c|c|}
\hline & \multicolumn{6}{|c|}{ Red table grapes } & \multicolumn{7}{|c|}{ White table grapes } & \multicolumn{3}{|c|}{ Red wine grapes } \\
\hline & PA & RF & RG & BEs & KRs & NR & KH & SC & EX & SL & CAs & CEs & SG & NB & BR & $\mathbf{A L}$ \\
\hline Caftaric acid & $\begin{array}{l}14.89 \\
\pm 0.36\end{array}$ & \begin{tabular}{|c|}
5.91 \\
\pm 0.12
\end{tabular} & $\begin{array}{c}10.54 \\
\pm 1.06\end{array}$ & \begin{tabular}{|c|}
10.93 \\
\pm 0.46
\end{tabular} & $\begin{array}{c}4.59 \\
\pm 0.16\end{array}$ & \begin{tabular}{|c|}
7.63 \\
\pm 0.19
\end{tabular} & \begin{tabular}{|c|}
7.22 \\
\pm 0.05
\end{tabular} & \begin{tabular}{|c|}
4.05 \\
\pm 0.18
\end{tabular} & \begin{tabular}{|c|}
7.69 \\
\pm 0.08
\end{tabular} & \begin{tabular}{|c|}
9.47 \\
\pm 0.78
\end{tabular} & $\begin{array}{c}14.21 \\
\pm 0.73\end{array}$ & \begin{tabular}{|c|}
15.36 \\
\pm 0.07
\end{tabular} & $\begin{array}{c}9.03 \\
\pm 0.49\end{array}$ & $\begin{array}{c}17.90 \\
\pm 0.55\end{array}$ & N.D. & N.D. \\
\hline Ruthin & N.D. & \begin{tabular}{|c|}
1.71 \\
\pm 0.04
\end{tabular} & $\begin{array}{c}1.49 \\
\pm 0.09\end{array}$ & N.D. & N.D. & N.D. & N.D. & N.D. & N.D. & N.D. & \begin{tabular}{|c|}
2.29 \\
\pm 0.07
\end{tabular} & \begin{tabular}{|c|}
0.54 \\
\pm 0.01
\end{tabular} & N.D.§ & $\begin{array}{c}1.60 \\
\pm 0.18\end{array}$ & \begin{tabular}{|c|}
1.14 \\
\pm 0.09
\end{tabular} & N.D. \\
\hline Hyperoside & N.D. & $\begin{array}{r}1.54 \\
\pm 0.01 \\
\end{array}$ & $\begin{array}{r}1.60 \\
\pm 0.10 \\
\end{array}$ & \begin{tabular}{|c|}
0.06 \\
\pm 0.02 \\
\end{tabular} & N.Q. & N.D. & N.Q. & N.D. & N.Q. & N.Q. & $\begin{array}{c}8.12 \\
\pm 0.27 \\
\end{array}$ & \begin{tabular}{|c|}
0.92 \\
\pm 0.03 \\
\end{tabular} & $\begin{array}{c}1.03 \\
\pm 0.05\end{array}$ & $\begin{array}{c}6.02 \\
\pm 0.39\end{array}$ & \begin{tabular}{|c|}
2.42 \\
\pm 0.35 \\
\end{tabular} & N.D. \\
\hline $\begin{array}{l}\text { Quercetin-3-O- } \\
\text { glucoside }\end{array}$ & $\begin{array}{c}8.35 \\
\pm 0.28\end{array}$ & $\begin{array}{c}16.44 \\
\pm 0.20\end{array}$ & $\begin{array}{c}14.87 \\
\pm 0.76\end{array}$ & \begin{tabular}{|c|}
5.82 \\
\pm 0.05
\end{tabular} & $\begin{array}{c}0.79 \\
\pm 0.03\end{array}$ & $\begin{array}{c}1.33 \\
\pm 0.01\end{array}$ & $\begin{array}{c}4.00 \\
\pm 0.03\end{array}$ & $\begin{array}{c}2.25 \\
\pm 0.02\end{array}$ & $\begin{array}{c}1.70 \\
\pm 0.04\end{array}$ & \begin{tabular}{|c|}
0.119 \\
\pm 0.003
\end{tabular} & $\begin{array}{c}63.80 \\
\pm 1.46\end{array}$ & \begin{tabular}{|c|}
9.65 \\
\pm 0.48
\end{tabular} & $\begin{array}{c}9.87 \\
\pm 0.34\end{array}$ & $\begin{array}{c}48.08 \\
\pm 2.80\end{array}$ & \begin{tabular}{c|}
23.94 \\
\pm 1.85
\end{tabular} & $\begin{array}{c}12.88 \\
\pm 1.39\end{array}$ \\
\hline $\begin{array}{l}\text { Quercetin-3-O- } \\
\text { glucuronide }\end{array}$ & N.D. & \begin{tabular}{|c|}
4.45 \\
\pm 0.12 \\
\end{tabular} & $\begin{array}{c}10.01 \\
\pm 0.44 \\
\end{array}$ & \begin{tabular}{|c|}
6.56 \\
\pm 0.24 \\
\end{tabular} & $\begin{array}{r}0.417 \\
\pm 0.003 \\
\end{array}$ & \begin{tabular}{|c|}
2.48 \\
\pm 0.05 \\
\end{tabular} & \begin{tabular}{|c|}
4.23 \\
\pm 0.06 \\
\end{tabular} & $\begin{array}{c}0.75 \\
\pm 0.03 \\
\end{array}$ & $\begin{array}{c}5.93 \\
\pm 0.01 \\
\end{array}$ & \begin{tabular}{|c|}
1.345 \\
\pm 0.002 \\
\end{tabular} & \begin{tabular}{|c|}
21.61 \\
\pm 0.06 \\
\end{tabular} & \begin{tabular}{|c|}
20.67 \\
\pm 0.98 \\
\end{tabular} & N.D. & $\begin{array}{c}8.39 \\
\pm 0.91 \\
\end{array}$ & \begin{tabular}{|c|}
21.05 \\
\pm 1.27 \\
\end{tabular} & $\begin{array}{c}6.69 \\
\pm 0.19 \\
\end{array}$ \\
\hline $\begin{array}{c}\text { Kaempferol-3-O- } \\
\text { glucoside }\end{array}$ & $\begin{array}{c}0.28 \\
\pm 0.06 \\
\end{array}$ & \begin{tabular}{|c|}
2.77 \\
\pm 0.09 \\
\end{tabular} & \begin{tabular}{|c|}
1.58 \\
\pm 0.09 \\
\end{tabular} & \begin{tabular}{|c|}
4.21 \\
\pm 0.06 \\
\end{tabular} & $\begin{array}{c}0.14 \\
\pm 0.002 \\
\end{array}$ & $\begin{array}{c}0.49 \\
\pm 0.01 \\
\end{array}$ & \begin{tabular}{|c|}
0.17 \\
\pm 0.02 \\
\end{tabular} & $\begin{array}{c}0.53 \\
\pm 0.01 \\
\end{array}$ & N.D. & N.D. & \begin{tabular}{|c|}
21.94 \\
\pm 0.30 \\
\end{tabular} & \begin{tabular}{|c|}
1.07 \\
\pm 0.06 \\
\end{tabular} & \begin{tabular}{|c|}
1.22 \\
\pm 0.09 \\
\end{tabular} & \begin{tabular}{|c|}
8.02 \\
\pm 0.42 \\
\end{tabular} & \begin{tabular}{|c|}
1.35 \\
\pm 0.09 \\
\end{tabular} & $\begin{array}{c}0.83 \\
\pm 0.08 \\
\end{array}$ \\
\hline Epicatechin & - & - & - & - & - & - & $\begin{array}{c}23.99 \\
\pm 0.36 \\
\end{array}$ & $\begin{array}{c}65.58 \\
\pm 0.24 \\
\end{array}$ & N.D. & N.D. & $\begin{array}{c}19.41 \\
\pm 2.19 \\
\end{array}$ & \begin{tabular}{|l|}
50.75 \\
\pm 4.40 \\
\end{tabular} & \begin{tabular}{|c|}
72.31 \\
\pm 3.15 \\
\end{tabular} & - & - & - \\
\hline Epicatechin gallate & - & - & - & - & - & - & N.D. & N.D. & $\begin{array}{r}34.50 \\
\pm 6.10 \\
\end{array}$ & \begin{tabular}{|l|}
53.87 \\
\pm 1.06 \\
\end{tabular} & N.D. & N.D. & N.D. & - & - & - \\
\hline Total Polyphenols & 1.057 & 0.643 & 1.558 & 1.059 & 0.438 & 0.650 & 1.478 & 0.880 & 2.865 & 0.505 & 1.405 & 1.979 & 0.808 & 3.851 & 4.080 & 7.940 \\
\hline Content & \pm 0.099 & \pm 0.037 & \pm 0.183 & \pm 0.073 & \pm 0.019 & \pm 0.036 & \pm 0.107 & \pm 0.031 & \pm 0.045 & \pm 0.003 & \pm 0.183 & \pm 0.203 & \pm 0.049 & \pm 0.072 & \pm 0.246 & \pm 0.191 \\
\hline
\end{tabular}

PA: Pasiga; RF: Red Flame; RG: Red Globe; BEs: Beauty seedless; KRs: King's ruby seedless; NR: Nerona; KH: King's Husainy; SC: Sugarone B.; EX: Exalta B.; SL: Sultanina; CAs: Canner seedless; CEs: Centennial seedless; SG: Sugarone; NB: Nebbiolo; BR: Barbera; AL: Albarossa; ND: Not detectable; NQ: Not quantifiable. Specific LOD and LOQ values are reported by Colombo et al. [16].

HPLC was lower than that deriving by Folin Ciocalteu's assay. The observed differences could be due to the known interferences coming from aromatic amines and sugars and leading to an overstimation of the total polyphenol content. In addition, the contribution of other phenolic compounds, not quantified by HPLC-DAD, should be taken in account, as previously reported [15].

\subsection{Assessment of the biological activity}

Since oxidative stress and inflammation are conditions closely correlated, the in vitro biological properties considered in this study were: 1) the free radical scavenging activity (measured by DPPH assay) and 2) the assessment of IL-8 release from gastric epithelial cells (measured by ELISA) [16].

\subsubsection{Free radical scavenging capacity: $D P P H$ assay}

Figure 3 shows the antioxidant activity of the grape samples, expressed as trolox equivalents $(\mathrm{mg} / \mathrm{g}$ fresh weight).

Among wine varieties, Albarossa showed the highest antioxidant activity $(10.92 \pm 0.08 \mathrm{mg} / \mathrm{g})$ followed by Barbera and Nebbiolo $(7.45 \pm 0.08$; and $4.88 \pm$ $0.18 \mathrm{mg} / \mathrm{g}$, respectively). As for table grapes, the highest free radical scavenging activity was found in the red variety Nerona $(4.88 \pm 0.18 \mathrm{mg} / \mathrm{g})$, followed by the white grape Exalta $(3.41 \pm 0.04 \mathrm{mg} / \mathrm{g})$. The lowest activities were found in the white table grape Sultanina $(0.32 \pm$ $0.001 \mathrm{mg} / \mathrm{g}$ ) and in the red table grape King's Ruby $(0.31 \pm 0.002 \mathrm{mg} / \mathrm{g})$. When the AOA was correlated with total polyphenol content (TPC), a good linear coefficient was obtained $\left(R^{2}=0.95\right)$, indicating that samples with high TPC showed also a high antioxidant activity (Fig. 4).

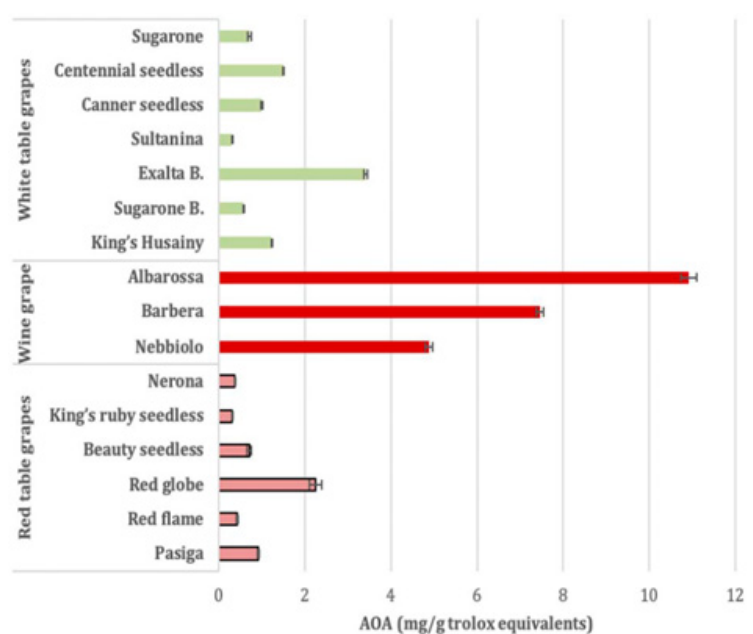

Figure 3. Free radical scavenging activity (AOA) measured by DPPH assay.

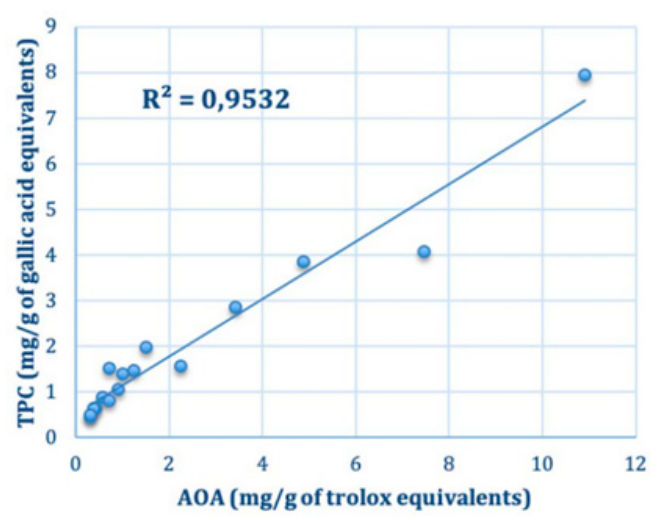

Figure 4. Correlation between TPC (mg/g gallic acid equivalents) and antioxidant activity ( $\mathrm{mg} / \mathrm{g}$ trolox equivalents). 


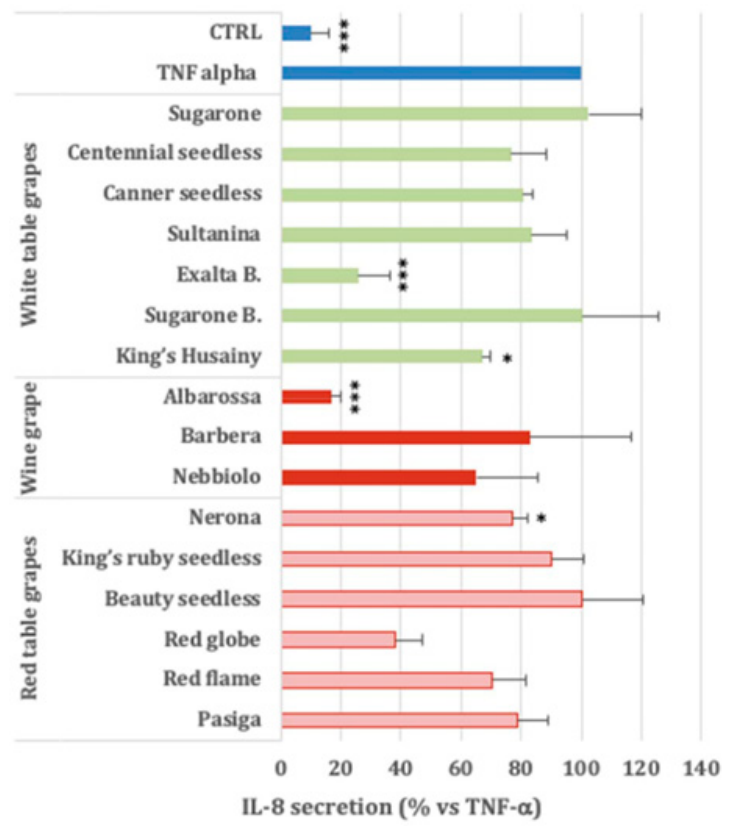

Figure 5. Screening of grape extracts activity on IL-8 release from AGS cells stimulated with TNF- $\alpha$ (pro-inflammatory stimuli). $* p<0.05$; $* * * p<0.001$ vs TNF- $\alpha$ alone. EGCG $20 \mu \mathrm{M}$ was used as the reference inhibitor of IL- 8 release (figure adapted from Colombo et al. [16]).

\subsection{Anti-inflammatory activity}

\subsubsection{Assessment of IL-8 release}

Grape extracts, prepared as described in paragraph 2.1, were assayed at the same concentration $(50 \mu \mathrm{g} / \mathrm{mL})$ to evaluate their ability to inhibit IL-8 release from human gastric hepitelial cells stimulated by TNF- $\alpha$. The results are reported in Fig. 5.

The red variety Albarossa and the white grape Exalta showed the highest activity, inhibiting IL-8 release by $85 \%$ and $75 \%$, respectively. For this reason, these varieties were selected for further investigations. In particular, each grape extract was assayed in the range of $5-100 \mu \mathrm{g} / \mathrm{mL}$ in order to evaluate the concentration capable to inhibit IL-8 release by $50 \%$ ( $\left.\mathrm{IC}_{50}\right)$; both Exalta and Albarossa (whole fruit) inhibited IL-8 release at very low concentrations $(8.48 \mu \mathrm{g} / \mathrm{mL}$ and $6.68 \mu \mathrm{g} / \mathrm{mL}$, respectively) (Fig. 6).

Finally, each part of Albarossa and Exalta grapes (peel, pulp, seeds) were assayed in order to evaluate the contribution to the anti-inflammatory activity. As showed in Fig. 7, both the peel and the seeds from Exalta and Albarossa showed to be the grape parts involved in inhibiting IL-8 release. In particular, the peel from Exalta showed an $\mathrm{IC}_{50}=9.77 \mu \mathrm{g} / \mathrm{mL}, 5$-fold lower than $\mathrm{IC}_{50}$ from Albarossa $(51.47 \mu \mathrm{g} / \mathrm{mL})$; on the other hand, the $\mathrm{IC}_{50}$ from Albarossa seeds was 2-fold lower than that from Exalta $(4.58 \mu \mathrm{g} / \mathrm{mL}$ and $8.31 \mu \mathrm{g} / \mathrm{mL}$, respectively). The pulp of both varieties was inactive.

These results could be at least partly explained by the high amounts of anthocyanins and flavanols detected in Albarossa and Exalta, respectively (Table 2); in fact, these compounds have been associated with several positive effects, including anti-inflammatory and antioxidant activity $[17,18]$. Interestingly, even though Exalta is classified as "seedless" variety, showed the presence of
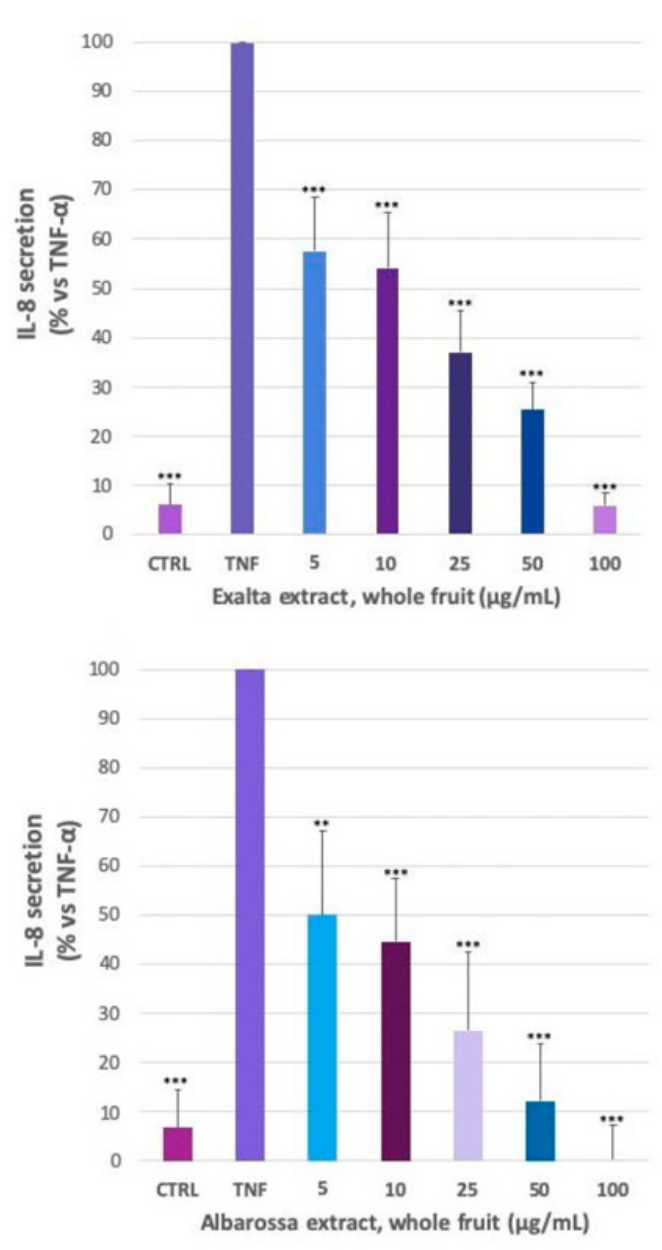

Figure 6. Exalta (upper panel) and Albarossa (lower panel) effects (whole fruit) on IL-8 release by AGS cells stimulated with TNF- $\alpha$ (pro-inflammatory stimuli). $* p<0.05 ; * * * p<0.001$ vs. TNF- $\alpha$ alone (figure adapted from Colombo et al. [16]).

Table 3. Correlation among $\mathrm{IC}_{50 s}(\mu \mathrm{g} / \mathrm{mL})$, AOA $(\mathrm{mg} / \mathrm{g})$ and $\mathrm{TPC}$ $(\mathrm{mg} / \mathrm{g})$ of the most active varieties (whole fruit).

\begin{tabular}{|c|c|c|c|}
\hline & $\boldsymbol{I C}_{\mathbf{5 0}}(\mu \mathbf{g} / \mathbf{m L})$ & AOA $(\mathbf{m g} / \boldsymbol{g})$ & $\boldsymbol{T P C}(\mathbf{m g} / \mathbf{g})$ \\
\hline Albarossa & 6.68 & 10.92 & 7.94 \\
\hline Exalta & 8.48 & 3.41 & 2.86 \\
\hline
\end{tabular}

undeveloped seeds (rich in flavanol compounds) which may have contributed to the biological activity.

In addition, a correlation between anti-inflammatory activity, and free radical scavenging capacity total polyphenol content was also observed (Table 3): for example, Albarossa, with the lowest $\mathrm{IC}_{50}$ (meaning highest anti-inflammatory activity), showed also the highest AOA and TPC.

These results show that: 1) polyphenols content is correlated with both antioxidant and anti-inflammatory activity; 2) AOA could be partly responsible for the inhibition of IL-8 release promoted by grape varieties; 3 ) if confirmed in vivo, these results suggest that grape consumption could reduce the oxidative stress generated during gastric inflammation.

\section{Conclusions}

In this study the phytochemical profile and the biological activity of sixteen varieties of grape samples (Vitis vinifera L.) were investigated. 

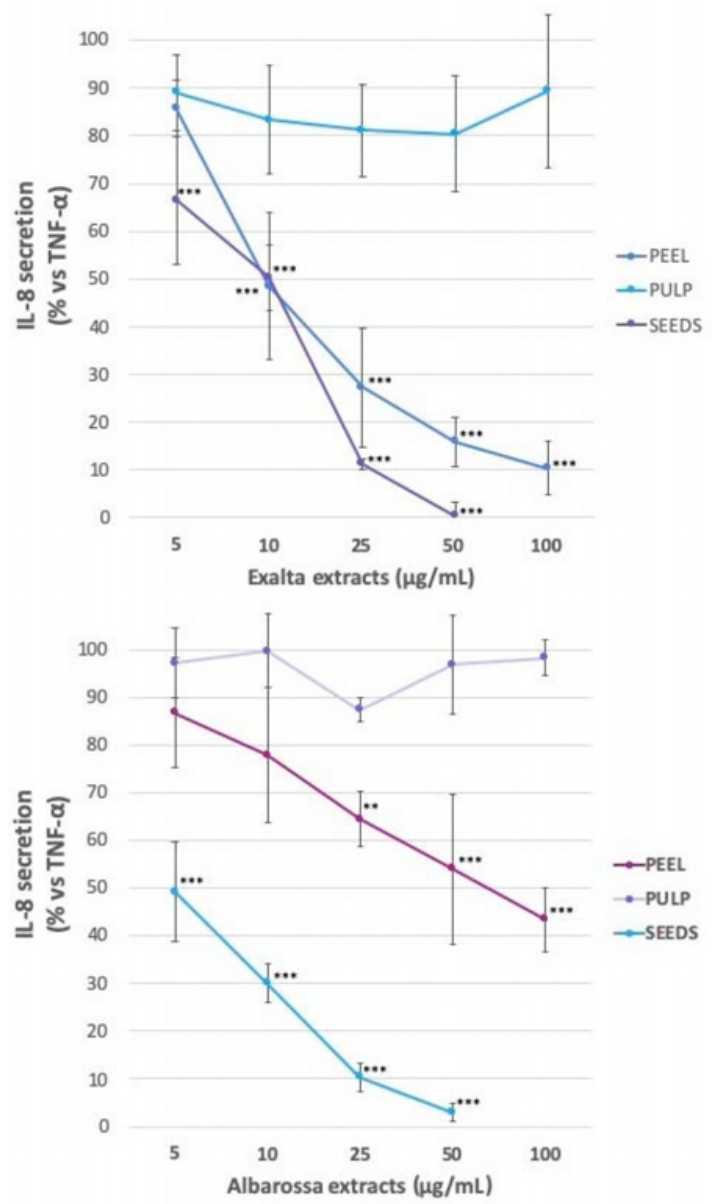

Figure 7. Effect on IL-8 release of peels, pulp and seeds from Exalta (upper panel) and Albarossa (lower panel) by AGS cells stimulated with TNF- $\alpha$ (pro-inflammatory stimuli). ${ }^{*} p<0.05$; $* * * p<0.001$ vs. TNF- $\alpha$ alone (figure adapted from Colombo et al. [16]).

A new aspect highlighted by the study was the interesting phenolic profile of some white grapes (e.g. Exalta and Centennial): although they are classified as "seedless", the presence of little undeveloped seeds was observed, due to the not completely successful parthenocarpic process used to produce seedless varieties. This phenomenon contributed to the considerable polyphenol content detected in these varieties, particularly in term of flavanols and flavanols. These compounds, abundant in the seeds [17], can be partly responsible for the correlated pattern of biological activity observed: the seeds from Exalta, significantly reduced IL-8 release from AGS cells as the seeded Albarossa $\left(\mathrm{IC}_{50}=8.48\right.$ and $4.58 \mu \mathrm{g} / \mathrm{mL}$, respectively). Antioxidant activity, measured by DPPH assay, was highly correlated to the anti-inflammatory activity, suggesting that the free radical scavenging capacity may be involved in the reduction of phlogistic processes occurring during gastric inflammation. These results could represent a starting point for a new research area involving selected seedless varieties that can both meet consumers' preferences (minor perception of the seeds) and, in parallel, provide higher amounts of compounds with anti-inflammatory and antioxidant activity.

Finally, taking into consideration the mean portion of grapes generally consumed in the Mediterranean area, our results suggest that the potential health effects could be maintained also in in vivo conditions, since the active concentrations measured in the study can be easily provided and reached the gastric levels. However, further studies will be developed in order to evaluate this aspect.

This research was supported by grants from MIUR Progetto Eccellenza.

\section{References}

[1] FAO-OIV, Focus 2016 Table and Dried Grapes, available to http://www.fao.org/3/a-i7042e.pdf (2016)

[2] WHO, Global Strategy to Reduce the Harmful Use of Alcohol, available to http://www.who.int/ substance_abuse/alcstratenglishfinal.pdf (2010)

[3] OIV, OIV Strategic Plan 2015-2019, available to http://www.oiv.int/public/medias/3345/ ps-2015-2019-en.pdf (2019)

[4] M.S. Fernández-Pachón, D. Villaño, M.C. GarcíaParrilla, A.M. Troncoso, Anal. Chim. Acta 513, 113 (2004)

[5] R.F. Pastor, P. Restani, C. Di Lorenzo, F. Orgiu, P.-L. Teissedre, C. Stockley, J.C. Ruf, C.I. Quini, N. Garcìa Tejedor, R. Gargantini, C. Aruani, S. Prieto, M. Murgo, R. Videla, A. Penissi, R.H. Iermoli, Crit. Rev. Food Sci. Nutr. 59, 1237 (2017)

[6] T. Shimada, A. Terano, J. Gastroenterol. 33, 613 (1998)

[7] G. Bonizzi, M. Karin, Trends Immunol. 25, 280 (2004)

[8] E. Sangiovanni, C. Di Lorenzo, E. Colombo, F. Colombo, M. Fumagalli, G. Frigerio, P. Restani, M. Dell'Agli, Food Funct. 6, 2453 (2015)

[9] C. Di Lorenzo, E. Sangiovanni, M. Fumagalli, E. Colombo, G. Frigerio, F. Colombo, L.P. de Sousa, A. Altindisli, P. Restani, M. Dell' Agli, Int. J. Mol. Sci. 17, e1156 (2016)

[10] V.L. Singleton, J.A. Rossi Jr., J.A. Rossi Jr., Am. J. Enol. Vitic. 16, 144 (1965)

[11] Brand-Williams, M.E. Cuvelier, C. Berset, Food Sci. Technol. 28, 25 (1995)

[12] L.P. Leong, G. Shui, Food Chem. 76, 69 (2002)

[13] E. Cantos, J.C. Espín, F. A. Tomás-Barberán, J. Agric. Food Chem. 50, 5691 (2002)

[14] E.S. Lago-Vanzela, R. Da-Silva, E. Gomes, E. García-Romero, I. Hermosín-Gutiérrez, J. Agric. Food Chem. 59, 8314 (2011)

[15] C. Di Lorenzo, F. Colombo, S. Biella, F. Orgiu, G. Frigerio, L. Regazzoni, L.P. de Sousa, L. Bavaresco, A. Bosso, G. Aldini, P. Restani, Bio Web Conferences 12, 04005 (2019)

[16] F. Colombo, C. Di Lorenzo, L. Regazzoni, M. Fumagalli, E. Sangiovanni, L. Peres de Sousa, L. Bavaresco, D. Tomasi, A. Bosso, G. Aldini, P. Restani, M. Dell'Agli, Food Funct. 10, 1797 (2019)

[17] X. Terra, V. Pallarés, A. Ardèvol, C. Bladé, J. Fernández-Larrea, G. Pujadas, J. Salvadó, L. Arola, M. Blay, J. Nutr. Biochem. 22, 380 (2011)

[18] F. Blando, N. Calabriso, H. Berland, G. Maiorano, C. Gerardi, M.A. Carluccio, O.M. Andersen, Int. J. Mol. Sci. 19, e169 (2018) 